\title{
El Solutrense en la zona pirenaica oriental *
}

\author{
SERGIO RIPOLL LOPEZ **
}

Una vez finalizada la Segunda Guerra Mundial, el problema del Solutrense y su origen empezaron a ser enfocados con una optica muy diferente a la del origen africano propuesta a raiz de las excavaciones de Miss Caton Thompson en Mugharet el'Aliya (Marruecos). A ello contribuyó sin duda una visión más completa del Musteriense y de las técnicas culturales que en él se desarrollaron (Caton-Thompson G. 1946).

El hallazgo de numerosos yacimientos petenecientes al Solutrense aportó un mejor conocimiento de sus industrias. Asimismo, la publicación a finales de los años $30 \mathrm{del}$ yacimiento de Laugerie-Haute permitió descubrir una serie de niveles que aportaban alguna luz a esta problemática. Actualmente resulta claro que el conjunto denominado como Presolutrense constituye una facies distinta dentro del propio tronco solutrense (Peyrony, D. y E. 1938).

La teoria sobre el foco originario en el Suroeste francés se basaba en que esta cultura poseía una tradición continuada desde el Protosolutrense pasando por el Solutrense Inferior hasta el Solutrense Superior, secuencia evolutiva que queda atestiguada en el yacimiento de LaugerieHaute (Peyrony, D. y E. 1938). Los niveles solutrenses más antiguos de Francia no tienen puntas foliáceas bifaciales, lo que sirvió de argumento para situar en este país uno de los focos de origen de esta cultura. 1988

" Trabajo presentado al "Congreso Internacional de Historia de los Prrineos. Cervera

** Departamento de Prehistoria e Historia Antigua, UNED. 
Esta teoria es la que quizás más adeptos ha encontrado, y en ella se habla de una evolución "in situ" de las industrias del Perigordiense Superior o Gravetiense. Esta postura admite dos matices: a) ó bien que todo el Gravetiense hubiese evolucionado progresivamente hacia el Solutrense, ó b) que únicamente lo hiciera en Francia y de ahi se difundiera hacia el resto de Europa. Esta hipótesis del origen francés ha sido mantenida por muchos investigadores entre los que se encontraba el abate Henri Breuil. Este investigador elaboró las bases de esta teoria al observar que en los yacimientos de La Ferrassie y Spy, los niveles gravetienses con puntas de La Font Robert, enlazaban con niveles con puntas de retoque invasor en la zona distal de la hoja.

D. Peyrony (1933) defendia la idea de que el Solutrense tendria su origen en la región del Gard desde donde pasaria a l'Ardèche, luego al Perigord y finalmente a la cornisa cantábrica y al resto de la Península Ibérica.

El último acercamiento al tema lo constituye la teoria de Ph. Smith (1966), en la que se revisan las estratigrafias solutrenses a partir de un hipotético Solutrense primitivo, en la que se entremezclan tradiciones musterienses y auriñacienes concretamente en los yacimientos de Badegoule y de Laugerie-Haute.

A partir del Solutrense Medio, este Protosolutrense se diversificaría en facies regionales que, ya tardias, son las que aparecen por todas las regiones de Francia y que pasaria a España, donde se dividiria en las dos zonas que son la cantábrica y la levantina.

El Protosolutrense, originado en la Dordoña, seria seguramente una rama del Perigordiense Superior Evolucionado, que habría absorbido técnicas de talla presolutrenses. El Solutrense típico vendría directamente del presolutrense de la Europa Central, sin que sepamos aún donde se originó, tal vez en el área de Dordoña-Pirineos, tal vez en España o tal vez en otros centros aún no hallados de la Europa Central.

Según Ph. Smith (1966) parece que el Solutrense no desciende del Perigordiense, sin bien no se debe negar a priori un posible contacto entre ambas culturas. Por otra parte el Protosolutrense se originó - posiblemente en la zona Sur del Ródano- a partir de un complejo o una variante local del Auriñaciense, que sufrió las influencias de un Musteriense prolongado. Este origen queda confirmado en yacimientos como La Grotte de Neron o el Abri Maras (Ardéche, Francia), excavados por J. Combier (1967). Desde este punto nació un Protosolutrense que se extendió hacia el Noreste y Suroeste francés, por una rutas no identificadas todavia. 


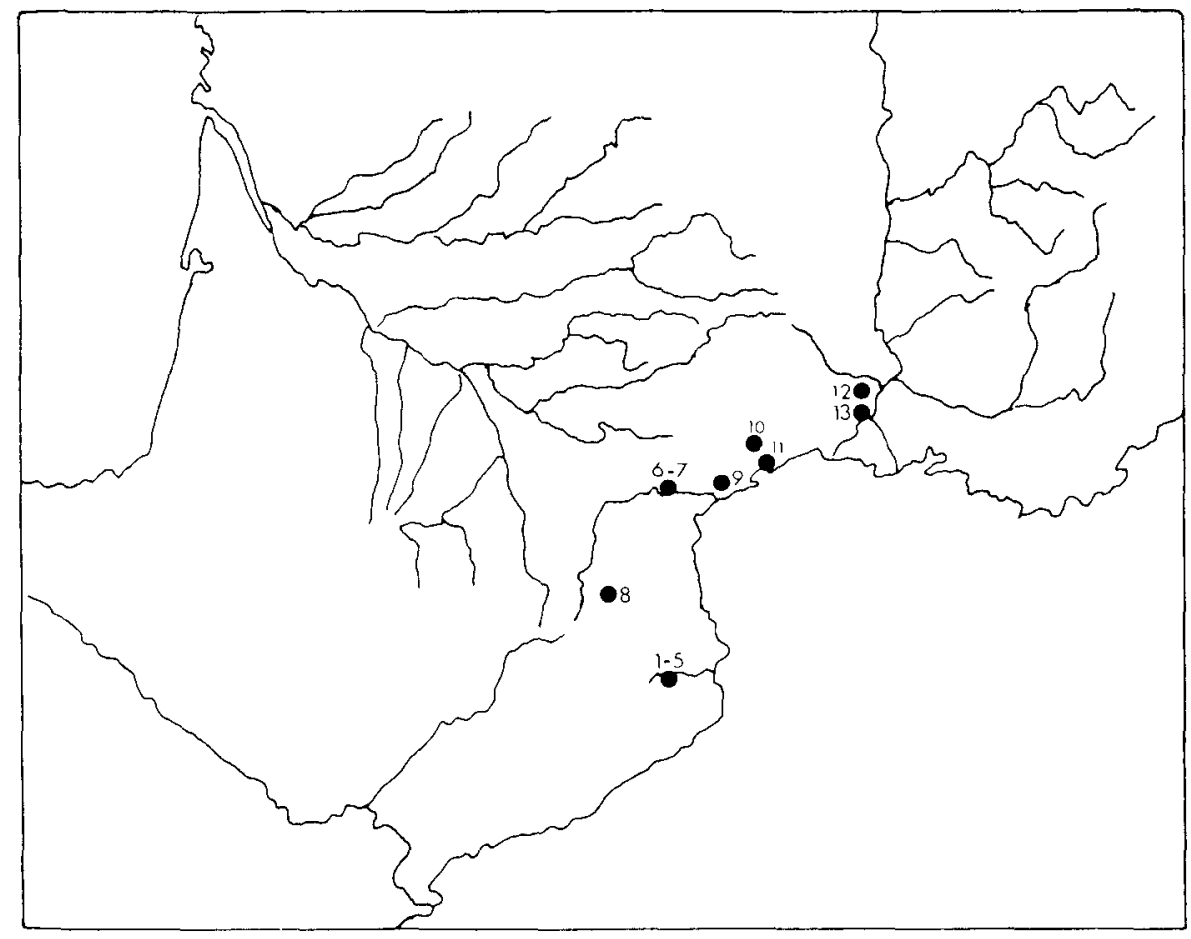

Fig. 1. Mapa de rep.micion de los yacimientos citados en el texto.

1. Reclau Viver. 2, LArbreda. 3. Davant Pau. 4, LEmbulada. 5. Cau de les Goges. 6, Petite Grotte De Bize. 7, Grande Grotte de Bize. 8. Grotte d'Embulla. 9. La Crouzade 10, La Roque. 11. Grotte du Col de Gigean. 12, La Salpétriere. 13. Grotte de Paques.

Parece ser que esta expansión se produjo posiblemente entre el final del Würm III y el inicio del interestadio Würm III-IV (Smith, Ph. 1966).

En cuanto al área de distribución de estas gentes, hay que señalar su ausencia al Oeste del Ródano, hacia los Alpes e Italia, donde es sustituido por el Epigravetiense antiguo con puntas foliáceas (Palma di Cesnola, A. 1967). En Europa Central hallamos algunas estaciones solutrenses y en particular en Hungria hay que citar la existencia de un Protosolutrense muy caracteristico.

En la Península Ibérica el Solutrense se presenta dotado de una gran diversidad tipológica, a pesar de las notables diferencias existentes 
entre la zona cantábrica y la mediterránea. En general, todos los hallazgos están relacionados con los fenómenos del Solutrense francés, aunque ofrecen sus puntas con pedúnculo con mayor frecuencia y no parece que la zona cantábrica quedase aislada de los otros centros solutrenses de la peninsula.

Uno de los aspectos que hay que señalar es que el Protosolutrense $y$ el Solutrense Inferior no existen en España, a excepción del dudoso nivel identificado en Les Mallaetes (Fortea, J. y Jordá, F. 1976) y que la fase más antigua se corresponde con el Solutrense Medio -tardio- de Francia.

Si el Protosolutrense o el Solutrense Inferior hubiese llegado a España desde Francia, en la Península Ibérica se tendrían que encontrar niveles de puntas de cara plana, pero sin hojas de laurel. Pero por el momento este hecho no se ha producido todavia; el Solutrense español más antiguo posee hojas de laurel: Parpalló, (Pericot, L. 1942) y Mallaetes, (Fortea, J. y Jordá, F. 1976).

Por otra parte, si los primeros solutrenses hubiesen llegado a España y posteriormente a Francia desde África del Norte, sería totalmente lógico encontrar piezas bifaciales como manifestación de una primera fase solutrense. Pero, es difícil de creer que, cuando los portadores de esta cultura tan desarrollada llegaron a Francia, abandonasen las hojas de laurel prefiriendo las puntas de cara plana, y no volviendo a utilizar aquellas hasta el Solutrense Medio.

Hay que destacar que si las más antiguas industrias solutrenses halladas en la Europa Occidental se inspiraron en los complejos musterienses de puntas foliáceas del Norte de África o de Europa Central, entonces los primeros útiles empleados por los solutrenses hubiesen sido las puntas foliaceas bifaciales. Pero el hecho de que tanto en Francia como en la Peninsula Ibérica las puntas foliáceas bifaciales esten precedidas en la secuencia cronoestratigráfica por niveles claramente solutrenses con puntas de cara plana (el Protosolutrense o Solutrense Inferior), demuestra que hay que buscar un origen diferente para esta industria. Sólo el hallazgo, que hasta el momento no se ha efectuado, de piezas solutrenses bifaciales por debajo de un nivel de puntas de cara plana, podria rebatir esta argumentación. Sin embargo, bien es cierto que en la Península Iberica, y concretamente en el yacimiento de la Cueva del Parpalló y en algunas estaciones de Francia, el nivel más antiguo es el de hojas de laurel o piezas bifaciales, pero este hecho tan sólo podría demostrar una difusión más tardia del Solutrense en estas regiones que en el resto de Europa. 
Tanto el Protosolutrense como el Solutrense Inferior son poco frecuentes y sus hallazgos están bastante restringidos geográficamente, lo que se debe probablemente a que los solutrenses no empezaron su verdadera expansión cultural hasta el Solutrense Medio. Esto hace pensar en la posibilidad de que realmente hubiese existido un período de cincubación" del Solutrense.

En definitiva, retomando las ideas expuestas por nosotros a raiz del Congreso sobre el Estrecho de Gibraltar (Ripoll López, S. 1988), pensamos que a pesar de que hubieran exisitido o no relaciones entre el continente africano y Europa, lo que nos llevaria a proponer un origen Ateriense, el Solutrense de la Península Ibérica es ligeramente más reciente que el francés, según nos muestran las dataciones de Carbono 14. Pero una vez vistas las diferencias existentes entre las distintas zonas, tanto desde el punto de vista cultural como desde el de las dataciones absolutas, no creemos que haya que buscar el origen del Solutrense francés en España, ni tampoco las raices del Solutrense español en Africa.

Nosotros creemos que pudo existir una determinada difusión de ideas culturales e industriales a partir del Solutrense Inferior desde la zona del Sur del Ródano (Ardèche) hacia las restantes zonas en las que se han localizado industrias solutrenses, pero el paso a otras facies de esta cultura se produciría mediante una evolución intrínseca de las formas originales y con una adaptación a las necesidades para las que eran realizados estos útiles. De esta forma aparecen las puntas de aletas y pedúnculo en el Solutrense español mientras que "en las zonas de origen" no se introduce este elemento.

En definitiva, podemos comprobar que el Solutrense en el Mediterráneo español, se desarrolló entre el $21.710 \pm 650$ B.P. del Solutrense Inferior de Les Mallaetes y el $16.500 \pm 280$ B.P. del Solutrense Superior Evolucionado de La Cueva de Ambrosio, ya que existen argumentos suficientes para pensar que la datación de $13.200 \pm 600$ B.P. de Reclau Viver, esté contaminada.

A lo largo del próximo apartado vamos a presentar una revisión de los yacimientos localizados en la zona del Pirineo Oriental en los que se han citado 0 existen evidencias de útiles solutrenses. Para esto nos hemos centrado en dos ámbitos muy concretos con hallazgos de este tipo de industrias como son el núcleo catalán y el ámbito del Languedoc en Francia. Estos trabajos están representados por las figuras de investigadores como N. Soler, D. Sacchi y M. Escalon de Fonton. 
La razón de haber querido incluir también la zona del Sureste francés es porque participa de las características industriales sensu lato del Solutrense del Mediterráneo Occidental. Este paralelismo del Sureste francés con el Mediterráneo de la Península Ibérica resulta particularmente evidente en las fases finales del Solutrense, que en aquella zona se ha individualizado con la denominación de Salpetriense, habiendo sido ya observado y propugnado por algunos investigadores como J. M. FuIlola (1978) y D. Sacchi (1986).

\section{EL SOLUTRENSE EN EL NÚCLEO CATALÁN}

Este momento cultural se ha localizado fundamentalmente en la cuenca del rio Serinyadell, próximo a la localidad de Serinyá (Gerona). Fuera de este importante núcleo, se han citado otros yacimientos que presentaban evidencias de útiles con retoque plano, pero estos, muchas veces no son indicativos del Solutrense.

En la zona de Serinyá, se conocen los yacimientos solutrenses del Reclau Viver, L'Arbreda, Davant Pau, Cova d'en Pau y Pau II o Cau d'en Paquito y en las proximidades, se descubrieron el Cau de les Goges y la Cova de l'Embulada.

Además, algunas veces se han citado otras estaciones en las que se han encontrado útiles con retoque plano como las puntas de flecha de Can Crispins, la de Tranquinell, la de Cassá de la Selva o la pieza foliácea de Caseta d'En Sureda que N. Soler (1986) cree que son postpaleolíticas.

Numerosos han sido los autores que han citado las piezas solutrenses de la Bora Gran (Pericot, L., 1952; Jordá, F. 1955; Pericot, L. y Maluquer, J., 1951). "Por si mismas no pueden confirmar la existencia de un Solutrense, pero tampoco se puede rechazar por el hecho de que algunas presenten más o menos pátina que los útiles magdalenienses. Podría tratarse de una reutilización de silex encontrados fuera del yacimiento" (Soler, N. 1986).

Con todos, los únicos datos fiables para el estudio del Solutrense en el ámbito catalán, son los del Reclau Viver, el Cau de les Goges y la Cova de l'Embulada. 


\section{Reclau Viver (Serinyà, Gerona)}

La cueva del Reclau Viver excavada por J. M. Corominas, proporcionó una secuencia muy completa del Paleolítico Superior. El nivel solutrense se desarrollaba entre 2,30 y 3 metros y se trataba de tierras negras con muchos restos óseos. Entre 2,30 y 2 metros, los restos líticos se hacian cada vez más escasos, lo que demostraba que la extinción del Solutrense en el Reclau Viver se había producido de una manera paulatina (Soler, N. 1986). J. M. Corominas, consideraba que todo el nivel se podia encuadrar dentro del Solutrense Superior por la presencia de puntas de muesca, pero algunos investigadores que han tratado sobre este importante yacimiento han expresado sus dudas. F. Jordá (1955) cree que estas industrias son comparables con el tramo superior del Cau de les Goges por la existencia de un microburil bastante tosco, que en la revisión del material, realizada por N. Soler (1986), no ha sido encontrado.

Corominas, veía en el Reclau Viver una clara influencia cantábrica -más que mediterránea- paralelizable con Cueto de la Mina por el apogeo de los tipos foliáceos romboidales y las azagayas con aplanamiento central.

El análisis detallado de la industria realizado por Marta Corominas, le llevó a ver dos momentos culturales claramente definidos: un Protosolutrense y un Solutrense Superior (Corominas, M. 1960). Estos dos estadios son plenamente aceptados por $N$. Soler (1986), que ha podido confirmar la estratigrafia con los sistemáticos y minuciosos análisis de la industria realizados para su Tesis Doctoral.

La revisión y estudio de estos materiales llevada a cabo por J. M. Fullola (1979) le permitió concluir que se trataba de un Solutrense Superior, en su fase media-final con elementos variados pero que conserva su ortodoxia.

Para el yacimiento del Reclau Viver, se cuenta con una datación de $13.200 \pm 600$ B.P. (RC 7, 147-8) (Crane, H. R., y Griffin, J. B. 1960, 1965, 1968) para el nivel entre 2 y 3,20 metros, atribuible al Solutrense Superior.

Esta datación resulta demasiado moderna, ya que nos situaria en un momento avanzado del Magdaleniense. Esta contemporaneidad cultural, no nos parecería extraña si la industria hallada en este nivel careciese de útiles de talla con retoque plano por presión y bifacial, pero no siendo así, es presumible que esta fecha esté contaminada. La simultaneidad en el desarrollo de distintas "culturas", es un hecho comprobado ya en dis- 

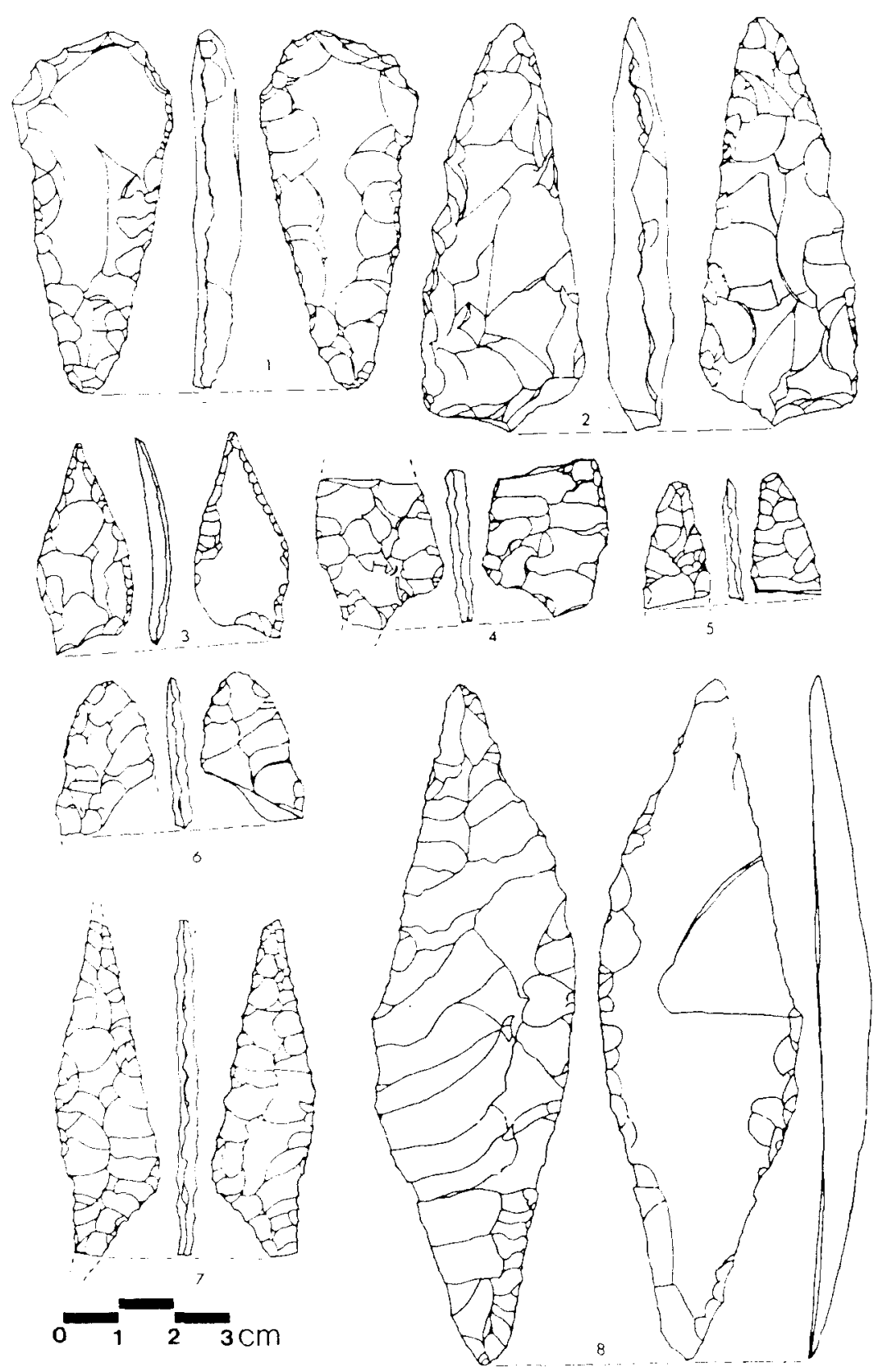

Fig. 2. Cueva del Reclau Viver. Industria litica procedente del nivel $F$, atribuido al Solutrense (según N. Soler). 
tintas regiones, de ahi que no resulte extraño que mientras en La Cueva de Ambrosio se está desarrollando el Solutrense Superior Evolucionado, en casi todos los yacimientos de la cornisa cantábrica ya se habia iniciado ampliamente el Magdaleniense.

Para N. Soler (1986), el Solutrense del Reclau Viver, así como el de los otros yacimientos de la zona, presenta una gran originalidad que impide acomodarlo a la secuencia clásica.

\section{L'Arbreda (Serinyà, Gerona)}

En esta cueva se han identificado como solutrenses los niveles 13 , 14, 15, y 16 del sector Alfa.

En este yacimiento el indice de foliáceos $(11,6 \%)$ es muy diferente al del Reclau Viver, ya que las únicas coincidencias entre las industrias de estos dos yacimientos se limitan a la presencia de la punta pedunculada asimétrica del nivel 16 de L'Arbreda y a las puntas de muesca, que en esta estación todas tienen retoque abrupto, siendo de tipo mediterráneo (Soler, N., 1986).

De cualquier forma, la escasez de restos hallados por J. M. Corominas en el sector Alfa es paralelizable a la pobreza observada por $N$. Soler en el sector Beta. Este nivel 16 atestiguaba una única y densa ocupación solutrense, y en él se encontró una magnífica hoja de laurel en silex rojo que nosotros incluiriamos dentro del subtipo B. Existen, también, algunos esbozos de puntas de aletas y pedúnculo y un fragmento de punta bifacial con pedúnculo desviado, muy parecida a las encontradas por $M$. Pallarés y P. Wernert (1915-1920) en el Cau de les Goges, y que estos últimos autores consideran fragmentos de puntas de escotadura.

Para el nivel atribuido al Solutrense, se han obtenido una serie de dataciones por diversos métodos, lo que unido a los resultados de las excavaciones llevadas a cabo en los últimos años en el yacimiento por N. Soler, han permitido encuadrar el Solutrense de L'Arbreda en un Solutrense Inferior (Soler, N. 1986):
La fecha de C-14 es de
$17.320 \pm 290$ B.P.
La fecha de U-Th es de
$13.000 \pm 3.000$ B.P.
La fecha de U-Pa es de
$10.000 \pm 4.000$ B.P.
La de electroresonancia es de
$22.000 \pm 6.000$ B.P. 

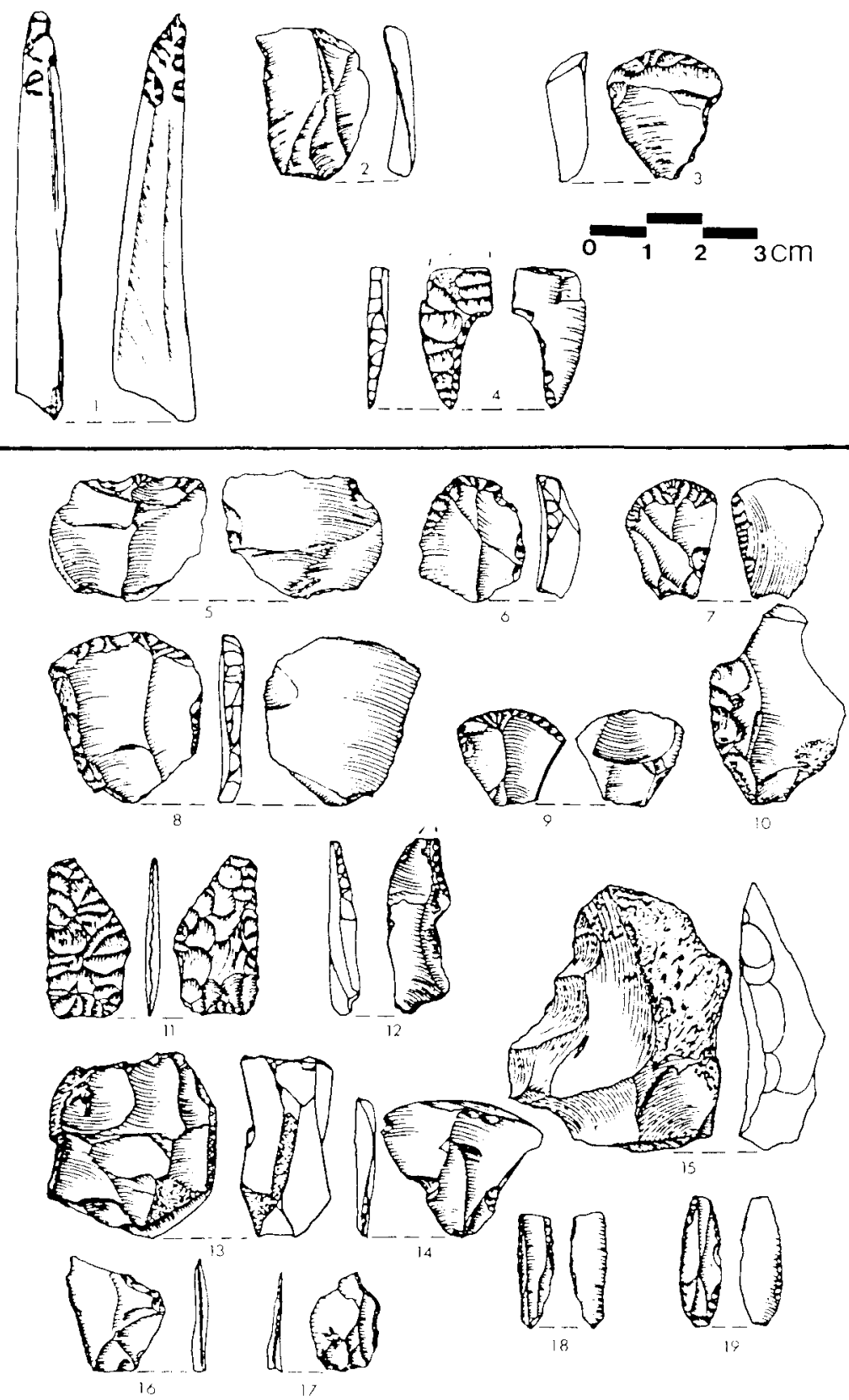

16

Fig. 3. Cueva de L'Arbreda, 1 a 4, industria litica del nivel 13, 5 a 19, industria litica del nivel 15, atribuidos al Solutrense (según N. Soler). 

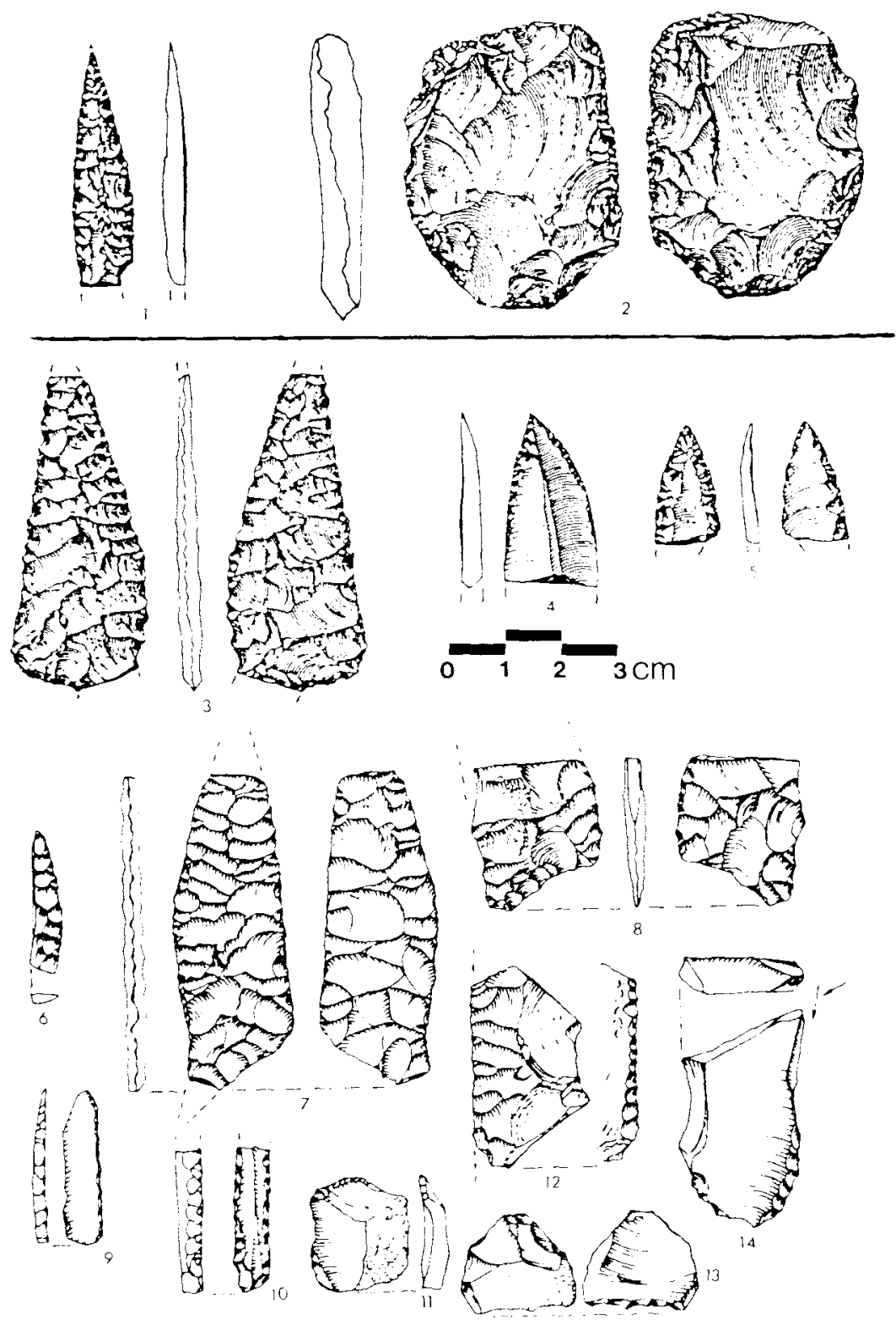

Fig. 4. 1 y 2, industria litica solutrense del nivel 10 de L'Arbreda, 3 a 13, industria lítica solutrense del yacimiento de Davant Pau (según N. Soler). 
Como vemos ninguna de estas fechas se relaciona entre si, aunque la de $\mathrm{C}-14$ es bastante coherente con el nivel al que corresponde, teniendo en cuenta el margen de error de la datación.

La atribución cultural no nos parece muy acertada, ya que no existen puntas de cara plana y sin embargo si se han encontrado útiles característicos de momentos posteriores como pueden ser las puntas de muesca. También las fechas de C-14 nos llevarian a proponer para este yacimiento un encuadre cultural correspondiente al Solutrense Medio o Solutrense Superior Inicial.

\section{Davant Pau (Serinyá, Gerona)}

En este pequeño yacimiento con varias bocas, lo que produce cierta confusión en cuanto a la denominación del mismo, se han localizado una serie de niveles que atestiguan una o varias ocupaciones solutrenses muy breves (Soler, N., 1986). El índice de las piezas foliáceas $(7,57 \%)$ es bastante escaso frente a los otros yacimientos, pero la presencia de una punta pedunculada y algunas puntas de muesca, permitiria relacionar de alguna manera el Solutrense de Davant Pau, con la unión del Solutrense Inferior y Superior del sector Alfa de L'Arbreda.

\section{Cova de L'Embulada (Gerona)}

Lo más significativo de este yacimiento es la presencia de una única hoja de laurel que Ph. Smith (1966) clasifica como de "tipo Rocacorbera", por su similitud con una punta ligeramente desviada y de base plana hallada en el yacimiento de Rocacorbera (Ariege). Para N. Soler (1986), la punta de L'Embulada es una punta pedunculada asimétrica con pedúnculo roto, que de tenerlo sería muy parecida a la del nivel 16 de L'Arbreda.

A falta de más datos, el Solutrense de esta estación sería sincrónico del Solutrense Inferior de la Cueva de L'Arbreda. Pero, creemos que con un indice de $10,30 \%$ de útiles sobre hojita no se puede encuadrar en un momento tan antiguo. 

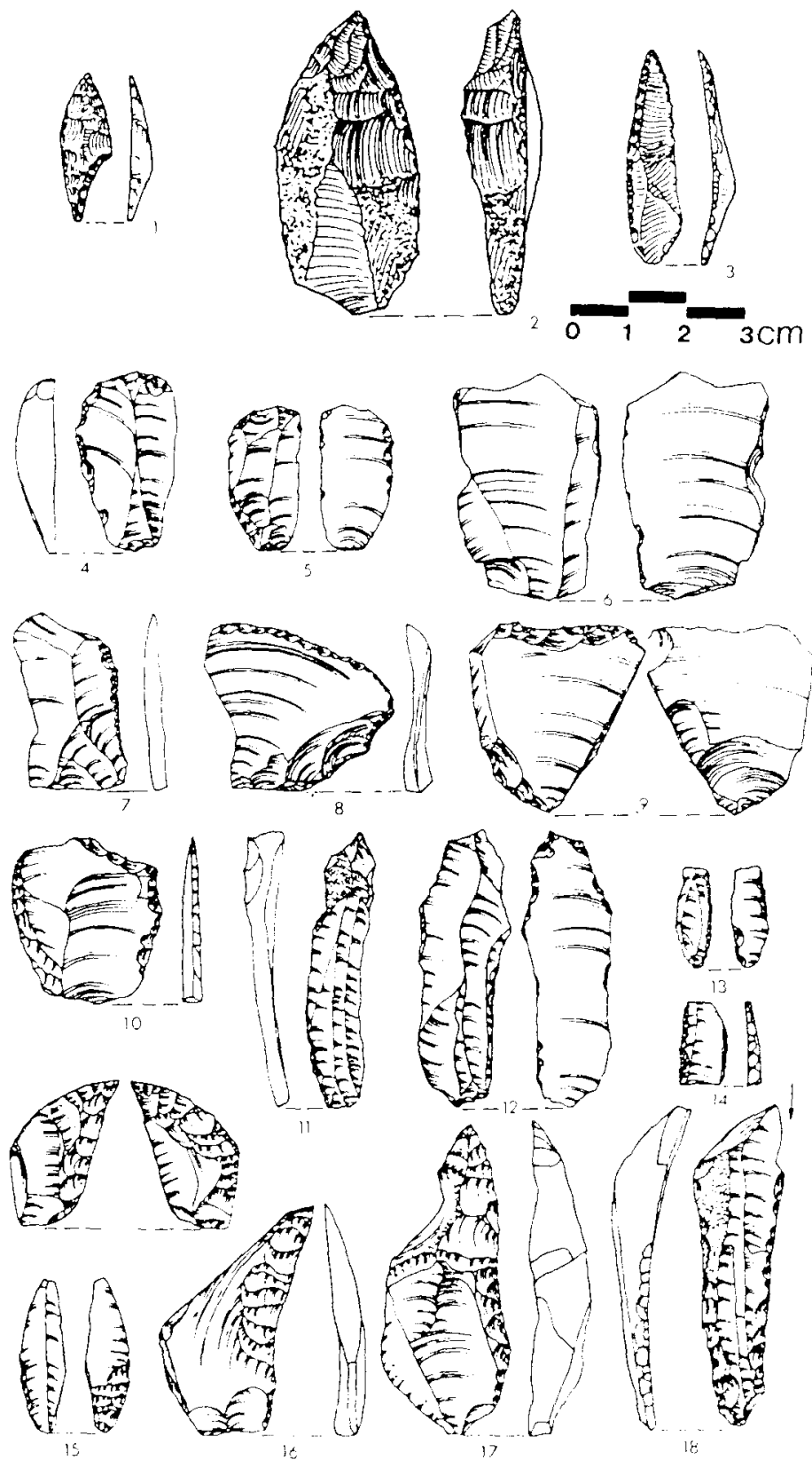

Fig. 5. Cueva del Cau de les Goges. Industria lifica procedente del nivel Solutrense (según N. Soler). 


\section{El Cau de les Goges (Sant Juliá de Ramis, Gerona)}

Este yacimiento excavado por M. Pallarés y $\mathrm{P}$. Wernert, proporcionó un Solutrense muy caracteristico y original. Se trata de un tipo especial de puntas bifaciales losángicas pedunculadas con aletas incipientes. L. Pericot (1942) hizo referencia a las mismas llamando a estos útiles de "tipo catalán", que para él tendian a adoptar forma de puntas neoliticas.

F. Jordá (1955) veia en el Cau de les Goges piezas de estilos musteriense, protosolutrense, gravetiense y solutrense y relacionaba las puntas romboidales con las halladas en el cantábrico, dependiendo ámbas zonas del Solutrense del Languedoc. Este mismo autor relacionó el nivel inferior del Cau de les Goges con la primera fase Solutrense de la cueva del Castillo. El tramo superior de este primer nivel y el segundo estrato se paralelizarian con los niveles inferiores del Reclau Viver

Para N. Soler (1986) el Solutrense del Cau de les Goges es posterior a) nivel $E$ del Reclau Viver y representa una facies cultural diferente a la de Serinyà, a pesar de la escasa treintena de kilómetros que las separa.

En definitiva, en el ámbito catalán podemos establecer una secuencia que se inicia con el Protosolutrense del nivel E del Reclau Viver. En un momento posterior, quizás una transición al Solutrense Inferior, se podría incluir el nivel inferior del Cau de les Goges, mientras que L'Arbreda, una parte de Davant Pau y la Cova de L'Embulada, se encuadrarian en un momento cultural correspondiente al Solutrense Inferior propiamente dicho.

El nivel superior del Cau de les Goges representaría una transición al Solutrense Superior, cuya fase más caracteristica o pura se encontraria en L'Arbreda, Davant Pau y en el vestibulo del Reclau Viver.

Con todo, las características de estos yacimientos estan más próximos a los del Sureste francés o cornisa cantábrica e incluso del Ariège que con los otros ámbitos del Mediterráneo español. Sin embargo el reciente hallazgo de puntas de muesca de tipo mediterráneo, establece ciertas conexiones con el resto del levante español.

\section{EL SOLUTRENSE EN EL LANGUEDOC}

El Solutrense en el ámbito del Languedoc queda atestiguado en una serie de yacimientos, algunos de cuales fueron excavados a finales del siglo pasado y otros después de la II Guerra Mundial. 


\section{La Petite Grotte de Bize (Aude)}

Sin ser el yacimiento más interesante, si hay que destacar por su industria La Petite Grotte de Bize (Aude), en la que E. Genson (1931) encontró, por debajo de un claro nivel Magdaleniense, otro estrato con 25 puntas de muesca de tipo mediterráneo, 1 hoja de laurel del subtipo $\mathrm{K}$ y 1 punta de cara plana. Si bien Genson atribuye este yacimiento a un momento cultural correspondiente al Solutrense Superior, parece ser que sus materiales eran producto de una mezcla del nivel solutrense con otro inferior gravetiense (Sacchi, D. 1986). El problema radica en si E. Genson no supo diferenciar los distintos niveles, o bien si se trataba de un mismo nivel.

Los restos líticos se acompañaban con una industria ósea relativamente abundante compuesta por 19 azagayas, entre las que dominan las de bisel simple estriado (6), y 9 punzones todos ellos muy característicos.

\section{La Grande Grotte de Bize (Aude)}

Muy próxima a esta última estación se halla La Grande Grotte de Bize (Aude), en la que en $1877 \mathrm{E}$. Cartailhac encontró una gran hoja de laurel que D. Sacchi cree que se trata de una pieza postpaleolitica (Sacchi, D. 1976). Posteriormente Ph. Héléna, Genson y otros investigadores atribuyeron este yacimiento al Protosolutrense, señalando la presencia de puntas de cara plana, hojas de laurel de tipo Montaud, puntas escotadas y también algunas puntas de aletas y pedúnculo. En el estudio realizado por Sacchi (1976), en el que se revisaba esta industria, se pudo comprobar que la mayoria de estos útiles habian desaparecido. Las piezas integrantes del grupo solutrense, conservadas en el Museo de Beziers, representan un $5,5 \%$ del total y está compuesto por una punta de cara plana y una punta de muesca de tipo mediterráneo. Este investigador sitúa el yacimiento en un Solutrense Superior, pero a nosotros nos parece que con las piezas conservadas actualmente es muy difícil poder dar una atribución cultural, cuando además no se tiene ningún otro tipo de estudio (sedimentologia, polen, $\mathrm{C}-14$, etc.).

\section{La Grotte de Embulla (Corneilla-de-Conflent, Pyrennées Orientales)}

Otra cueva situada en el Sureste francés con una atribución cultural al Solutrense Superior es La Grotte de Embulla (Corneilla-de-Conflent, 

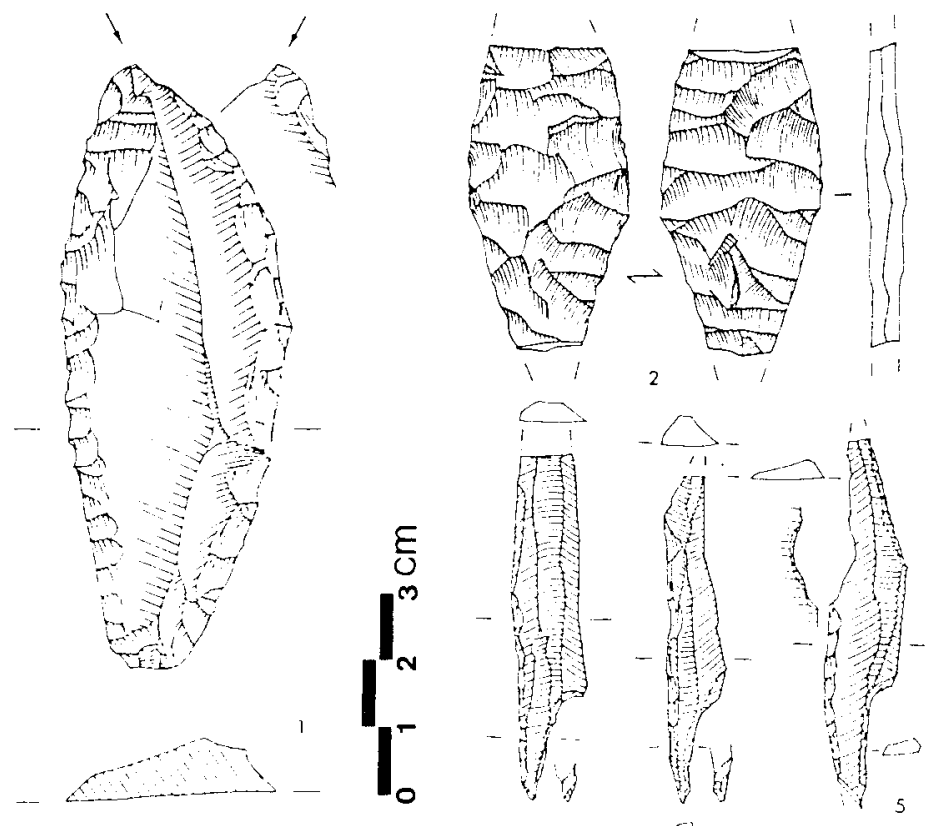

- (i) - 3 C C 4
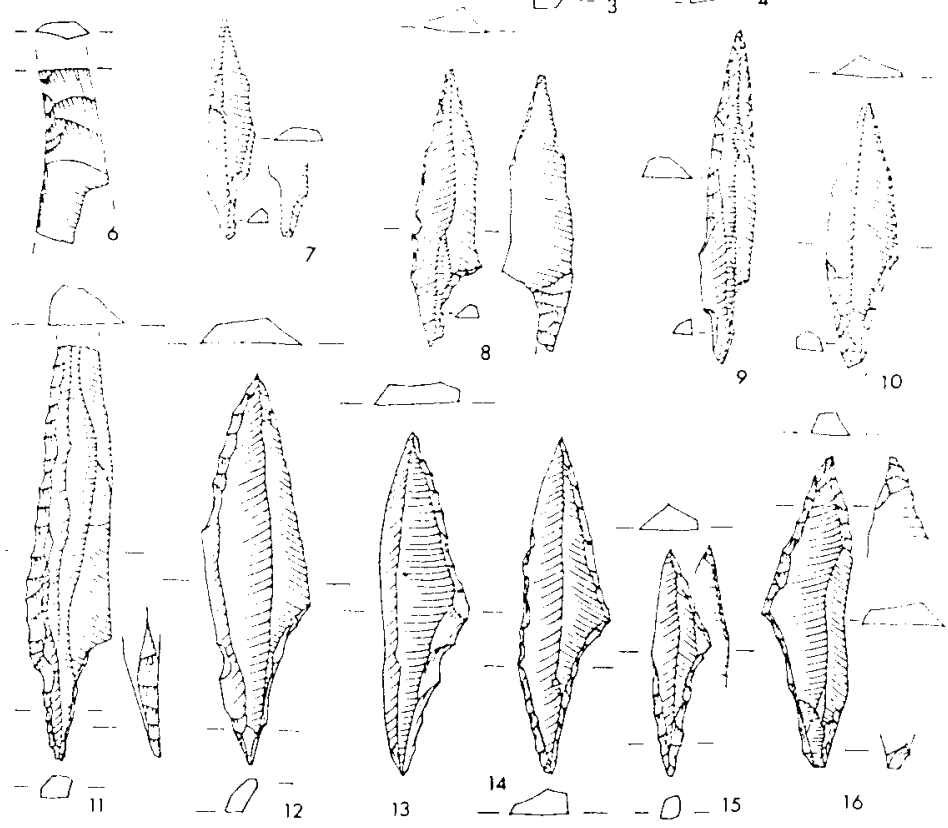

Fig. 6. Petite Grotte de Bize. Industria litica atribuida al Solutrense Superior (según D. Sacchi). 

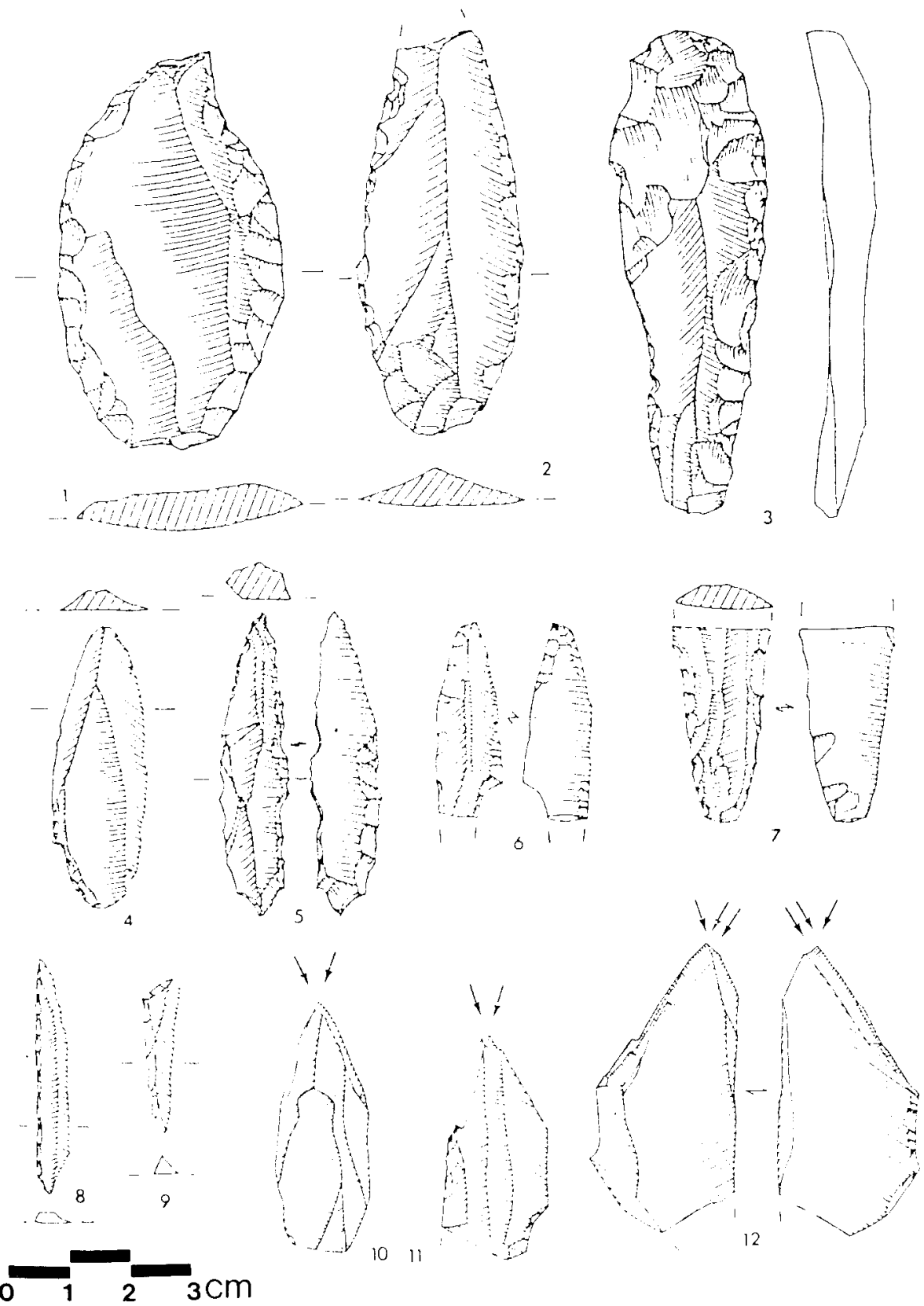

Fig. 7. Grande Grotte de Bize. Industria litica atribuida al Solutrense Superior (seguin D. Sacchi). 
Pyrennées Orientales) que fue excavada por J. Abelanet en 1954 y 1955 En ella se encontró un nivel con industrias solutrenses, en el que el grupo indicador de esta cultura está representado por un $7,21 \%$. Los tipos identificados son 1 punta de cara plana del subtipo C, 4 puntas de cara plana del subtipo E, 1 hoja de laurel y 1 punta de muesca mediterránea (Sacchi, D. 1986). Dada la existencia de un porcentaje tan alto de puntas de cara plana, resulta dificil aceptar su atribución al Solutrense Superior. pero la existencia de la punta de muesca y de un grupo de útiles sobre hojita con un indice de $10,30 \%$ nos hace pensar que el encuadre cultural es correcto. Sin embargo, no deja de ser sorprendente el alto porcentaje de las puntas de cara plana.

\section{La Grotte de la Crouzade (Gruissan, Aude)}

Otro yacimiento de la zona en el que se han citado materiales solutrenses es La Grotte de la Crouzade (Gruissan, Aude), en la que E. Genson encontró en la escombrera una pieza hoy desaparecida. D. Sacchi (1986) señala la existencia de esta hoja de laurel "tipo Montaud" que nosotros creemos que se trata de un subtipo $F$, y son muy parecidas a las halladas por J. M. Corominas en el yacimiento del Reclau Viver.

Ph. Smith (1966) hace referencia a esta pieza y muestra su extrañeza de que aparezca tan alejada del yacimiento de Montaud y la relaciona con las hojas de laurel asimétricas del subtipo $\mathrm{F}$ del yacimiento catalán antes citado.

También cita Ph. Smith (1966), el yacimiento de La Roque (Frontignan. Herault) en el que se encontraron algunos útiles solutrenses.

El mismo autor indica que La Grotte du Col de Gigean (Frontignan, Herault), donde se encontraron un fragmento de hoja de laurel, dos pequeñas puntas de cara plana y una "bella punta de flecha bifacial de tipo solutrense" (Boudou y Vidal 1958), sería un intermediario entre la región de Gard-Ardèche y el Suroeste francés.

Como podemos comprobar el Solutrense en este ámbito no puede ser analizado en toda su extensión dada la escasez de materiales con que actualmente se cuenta. Esperamos que las excavaciones e investigaciones que en la actualidad se están llevando a cabo por $F$. Bazile y D. Sacchi, permitan revalorizar este momento cultural tan importante como "puente" entre el ámbito catalán y uno de los posibles núcleos originarios de la misma, como es el núcleo del Ardèche. 

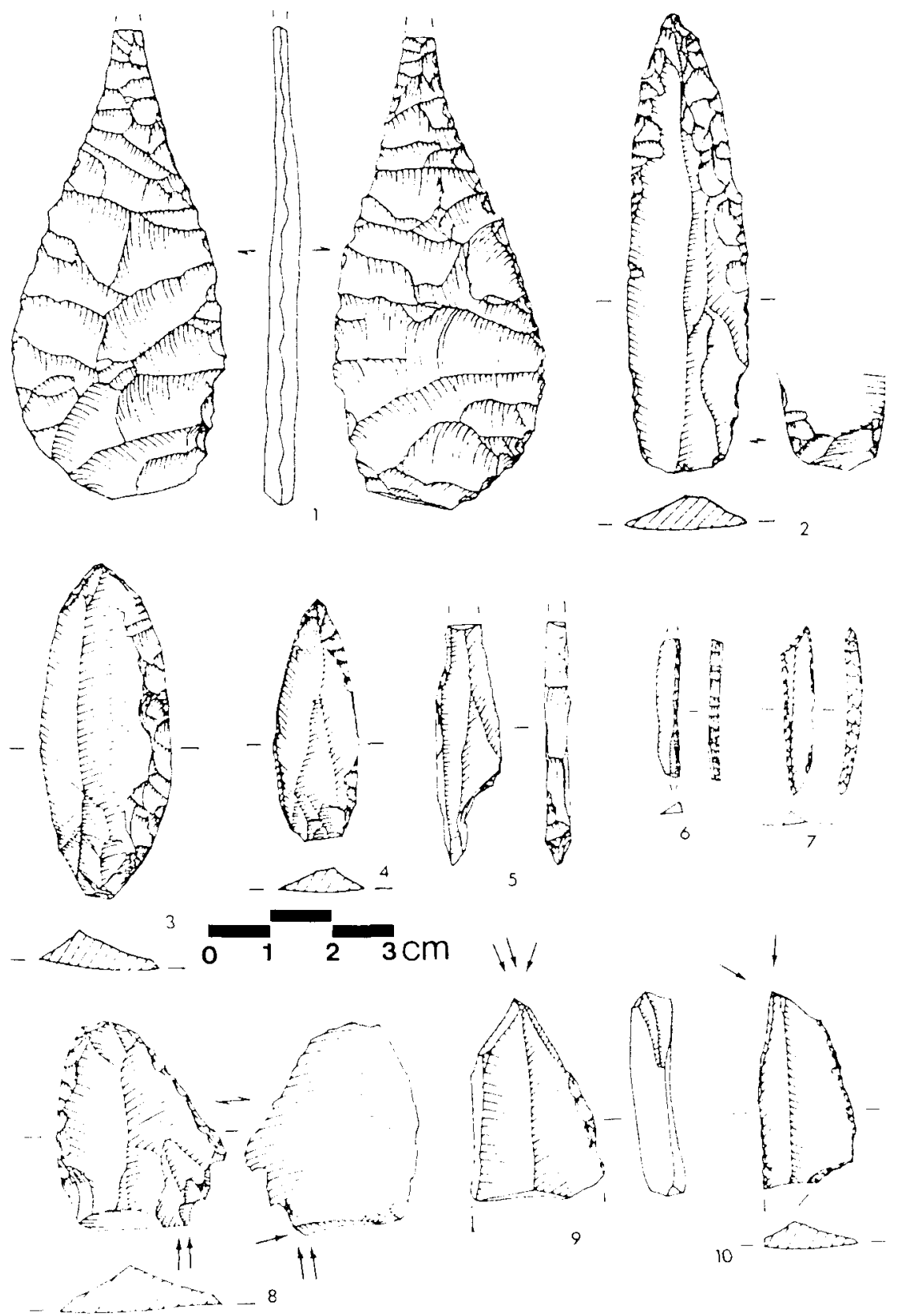

Fig. 8. Grotte d'Embulla. Industria litica atribuida al Solutrense Superior (según D. Sacchi). 
Entre este núcleo del Rosellón y el de l'Ardèche se encuentran dos yacimientos de gran interés por su situación y uno de ellos por sus caracteristicas industriales. Se trata de La Salpetrière, que ha proporcionado la secuencia más completa del Solutrense en el Sureste francés.

\section{La Salpetrière (Remoulins, Gard)}

En esta estación se identificaron una serie de niveles que abarcaban desde el Solutrense Inferior hasta el Solutrense Superior Evolucionado, que en esta cueva poseia unas caracteristicas especiales, que llevaron a M. Escaion de Fonton a denominar a esta facies con el término epónimo de Salpetriense (Escalon de Fonton, M. 1964).

Las excavaciones realizadas por este investigador en el yacimiento se centraron en el testigo dejado por el abate Bayol. En la base del mismo se encontró un nivel Solutrense «inferior», en el que el único integrante del grupo solutrense eran las puntas de cara plana, estando en algunos casos la cara bulbar ligeramente retocada.

En el segundo nivel los útiles solutrense (aigunas puntas de cara plana y fragmentos de hoja de laurel) junto con una datación radiocarbónica (Ly-940: 20.200 $1600 \mathrm{BP}$ ), han permitido encuadrario en un Solutrense Medio. En esta zona no se encontró el Solutrense Superior, posiblemente suprimido por la erosión que separa los niveles solutrenses de los salpetrienses (Evin, J. y Marien, G. 1971).

Los niveles salpetrienses excavados en otra zona de la cueva permitieron definir esta facies cultural. El Salpetriense aparece estratigráficamente entre el Solutrense Medio y el Magdaleniense V. Se puede dividir en 2 estadios: a) el Salpetriense inferior, que ocupa el espacio cultural del Solutrense final del Languedoc occidental y Provenza, perviviendo paralelamente hasta el Magdaleniense I y II; el b) el Salpetriense Superior contemporáneo a su vez del Magdaleniense III y IV.

El Salpetriense Inferior se podria comparar fácilmente con el Solutrense Evolucionado, en el que estan ausentes los piezas solutrenses típicas. Las puntas de muesca de tipo mediterráneo aumentan con un indice de más del $10 \%$. Las puntas pedunculadas estan representadas con un $5 \%$, y tanto las hojitas de dorso (11\%) como los buriles tienen una representación muy alta, incluso por encima de los raspadores (IR/ $\mathrm{IB}=2,06 \%$ ). 

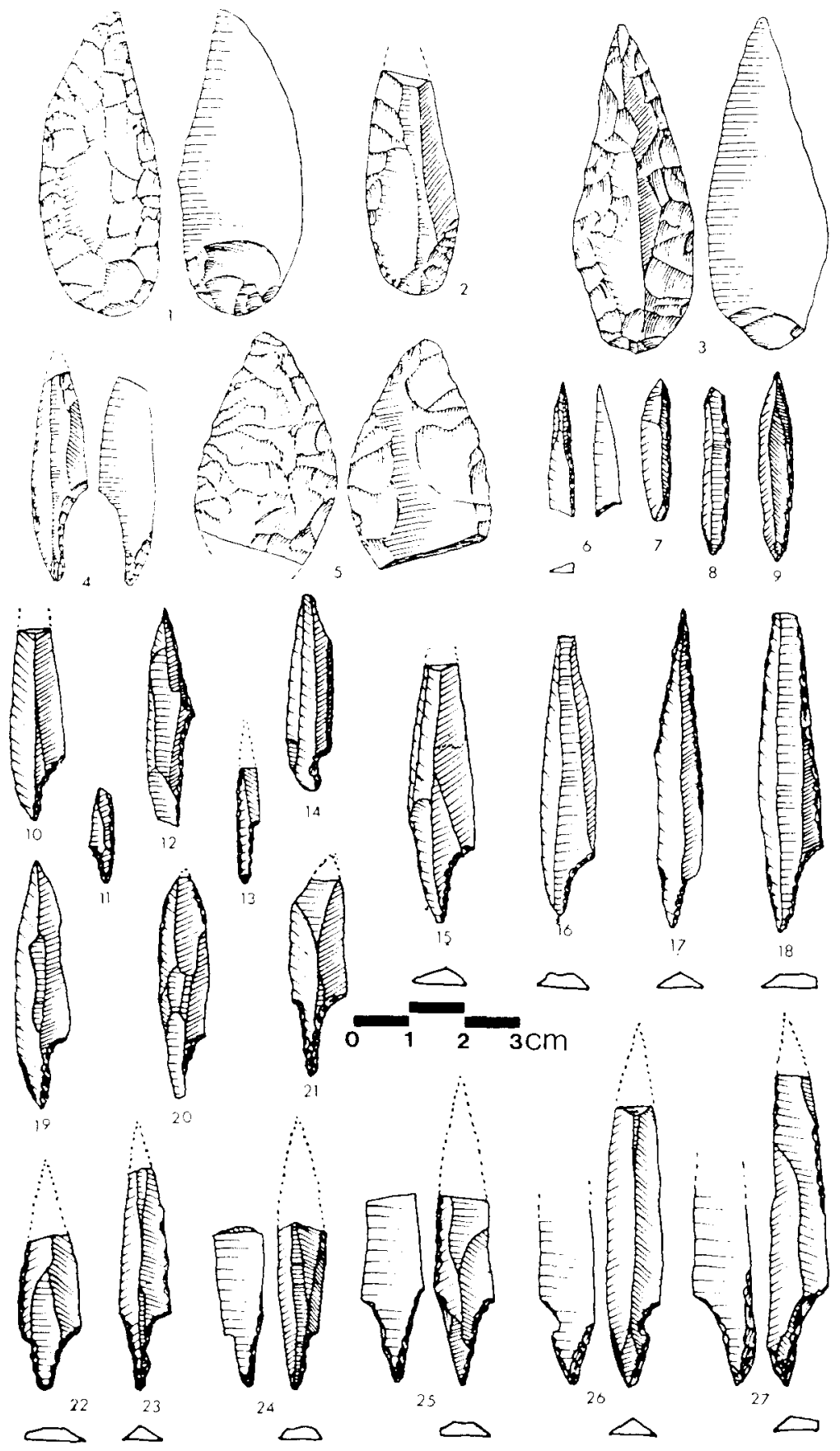

Fig. 9. La Salpetrière. Industria lítica del Salpetriense Inferior (según Escalon de Fonton). 
Según Escalon de Fonton (1946) "el estudio técnico y tipológico del Salpetriense parece confirmar su ascendencia solutrense". En el Languedoc y Provenza el Salpetriense sustituye al Solutrense Superior, probablemente porque se obligó al Solutrense a adaptarse a un medio diferente al que podia adaptarse. De cualquier forma la ocupación de la Salpetrière no fue seguramente muy larga, como afirma Bonifay, ya que algunos siglos pudieron ser suficientes para acumular el sedimento del Solutrense de este yacimiento (Escalon de Fonton, M. y Bonifay, E., 1958).

\section{La Grotte de Pâques (Collias, Gard)}

El otro yacimiento situado en esta zona es La Grotte de Pâques, en el que según G. Ravoux y F. Bazile (1967) el abate Bayol, excavador del yacimiento, mezcló todos los materiales. Posteriormente F. Bazile (1979) consiguió diferenciar los materiales solutrenses de los del siguiente nivel, encuadrable en un Magdaleniense, por la pátina y el gran tamaño de los útiles foliáceos.

De esta forma queda configurado el Solutrense en esta zona de paso entre el Languedoc y L'Ardèche a la espera de nuevos datos y descubrimientos que aporten alguna luz a su conocimiento.

Dentro de la configuración general del Solutrense en el Mediterráneo Occidental, se aprecian una serie de diferencias que se manifiestan de un modo especial en las características industriales de algunos tipos de útiles.

Estas diferencias se basan fundamentalmente en la existencia o no de retoque plano sobre las puntas de muesca y el aspecto "más clásico" de las industrias. Además esta divergencia se acentúa en el último momento del Solutrense, que en área mediterránea tiene unos "fósiles directores" muy característicos como son las puntas de aletas y pedúnculo y las puntas de muesca con retoque abrupto, mientras que en el área cantábrica, esta última fase se enmarca ya en el Magdaleniense. En el Sureste de Francia, el Solutrense Superior Evolucionado es sustituido por el Salpetriense, que si bien presenta puntas de muesca de tipo mediterráneo, no introduce las puntas de aletas y pedúnculo. De igual forma en el área catalana aparecen de una forma más o menos intrusiva las puntas de muesca con retoque plano, que lo liga, tanto por su proximidad geográfica como industrial, al Pirineo francés. 
Las numerosas campañas de prospección que se estan llevando a cabo, tanto en la Península Ibérica como en el Sureste francés, permitirán en un futuro próximo poner en evidencia los puntos de conexión entre ambas zonas - si existieron--, y de esta forma averiguar si la influencia cultural se realizó desde el Noroeste al Sureste o al contrario. De cualquier forma creemos que esta revisión del Solutrense en los Pirineos Orientales, servirá de base para futuras investigaciones, muchas de las cuales ya estan en curso. 


\section{BIBLIOGRAFIA}

BAZILE, F., 1975: “Nouvelles données sur l'abri sous roche de la Salpetrière (Remoulins, Gard)". BSPF, tomo 42, 1975, pág. 22-23.

- 1976: "Recherches sur le Paléolithique Supérieur ancien "Presolutréen" en Languedoc Oriental». BSPF, tomo 73, pág. 226-227.

- 1977: "Nouvelles données sur le Paléolithique Supérieur ancien en Languedoc Oriental». Congrès Préhistorique de France. Compte rendu de la XX Session, Provence, 1974, Paris, 1977, pág. 24-28, 3 figuras.

- 1979: "Le Paléolithique Supérieur en Languedoc Oriental. Etat des recherches, próblemes généraux". Ecole Antique de Nimes, Bulletin annuel, núm. 14. Nimes 1979, pág. 11-25, 16 figuras.

- 1980: «Precisions chronologiques sur le Salpetrien Ses relations avec le Solutréen et le Magdalenien en Languedoc Oriental». BSPF, tomo 77, 1980, pág. 50-56.

CAton-Thompson, G., 1946: "The Aterian industry: its place and significance in the Palaeolithic world". (Huxley Memorial Lecture for 1946). Journal of Royal Antiquities Institut (Londres), tomo LXXVI, 1946, pág. $87-130$

COMBIER, J., 1959: “La structure du Paléolithique Supérieur dans la region du Rhone moyen». C.R. Acad. Sc. Paris, tomo 250, 1959, pág. 1889-1891.

- 1967: Le Paléolithique dans l'Ardèche. Edit Delmas, Burdeos 1967, 452 páginas, 174 figuras

Corominas, J. M., 1946: "La Cueva del Reclau Viver, Seriña, Gerona". Anales del Instituto de Estudios Gerundenses (Gerona), tomo 1946, pág. 209-223.

- 1950: "Puntas pedunculadas asimétricas del nivel solutrense de Reclau-Viver de Serinya". I Congreso Arqueológico Nacional y $V$ del Sudeste, 1950, pág. 41-46. 
Corominas, M., 1960: “El Solutrense del Reclau Viver de Seriñá». Memoria de Licenciatura en la sección de Historia de la Facultad de Filosofía y Letras, Curso 1959-1960. Barcelona 1960, original inédito.

Crane, H. R. y Griffin, J. B., 1960: University of Michigan Radiocarbon dates, tomo V, Michigan, 1960.

- 1965: University of Michigan Radiocarbon dates, tomo X, Michigan 1965.

- 1968: University of Michigan Radiocarbon dates, tomo XII, Michigan, 1968.

DelibriAs, G. y EVIN, J., 1974: “Sommaire des datations 14C concernant la Préhistoire en France. I.-Dates parues de 1955 à 1974». BSPF, tomo LXXI, 1974, pág. 149-156.

- 1980: "Sommaire des datations 14C concernant la préhistoire en France». BSPF, tomo 77, 1980, pág. 215-224.

ESCALON DE FONTON, M., 1964: “Un nouveau faciès du Paléolithique Supérieur dans la grotte de la Salpetrière (Remoulins, Gard)". Miscelánea en homenaje al Abate Henri Breuil (1877-1961), tomo I, Barcelona, E. Ripoll, edit., 1964, pág. 406-421, 9 figuras.

- 1970: "Le Paléolithique Supérieur de la France Méridionale". Congrés sur l'Homme de Cromagnon, 1968, París 1970, pág. 45-52.

ESCALON DE FONTON, M. y BONIFAY, E., 1957: “Les niveaux solutréens de la grotte de la Salpetrière". L'Anthropologie, tomo LXI, París, 1957, pág. 207-238, 15 figuras.

Escalon de Fonton, M. y BazILE, F., 1976: "Les civilisations du Paléolithique Supérieur en Languedoc Oriental». La Préhistoire Française, CNRS, Paris 1976, pág. 1163-1174.

Escalon de Fonton, M. y Onoratini, G., 1976: "Les civilisations du Paléolithique Supérieur en Provence littorale». La Préhistoire Française, CNRS, París 1976, pág. 1145-1157.

EVIN, J., Marechal, J. y Marien, G., 1983: "Lyon natural radiocarbon measurements». Radiocarbon, núm. 25, 1983, pág. 59-128.

EVIN, J. y MARIEN, G., 1974: "Essai de datage par le radiocarbon des couches paléolitiques supérieures du gisement de la Salpetrière (Gard)". Congrés Préhistorique de France, XX session, Provence, París 1974, pág. 248-250.

ForteA, J. y JORDA, F., 1976: "La Cueva de Les Mallaetes y los problemas del Paleolitico Superior del Mediterráneo español». Zephyrus (Salamanca), tomo XXVI-XVII, 1976, pág. 127-166, 11 figuras.

Fullola Pericot, J. M., 1978: “El Solutreo-Gravetiense o Parpallense, industria mediterránea". Zephyrus (Salamanca), tomo XXIV, 1978, pág. 113-125. 
- 1979: “Las industrias líticas del Paleolítico Superior Ibérico». SIP, Trabajos Varios, núm. 60, 262 páginas, con figuras y láminas.

JoRdÁ Cerdá, F., 1955: El Solutrense en España y sus problemas. Oviedo, Servicio de Investigación Arqueológica de la Diputación Provincial de Asturias, 200 páginas, IV láminas.

Jordá CerdaÁ, F. y Fortea Pérez, J., 1976: “El Paleolítico Superior y Epipaleolítico del Mediterráneo español en el cuadro del Mediterráneo Occidental». IX Congrés de la UISPP Nice 1976, Resumé des communications, pág. 99-127.

Pallares, M. y Wernert, P., 1920: “El Solutrià de Sant Julià de Ramis: el Cau de les Goges". Anuari de l'Institut d'Estudis Catalans (BarceIona), tomo VI, 1920, pág. 349-355.

Pericot Garcia, L., 1942: La Cueva del Parpalló (Gandia). Excavaciones del Servicio de Investigación Prehistórica de la Diputación de Valencia. Madrid, CSIC, Instituto Diego Velázquez, 1942, 351 páginas.

- 1952: “Nueva visión del Paleolítico Superior español y de sus relaciones con el sur de Francia e Italia". Atti del I Congresso Internazionale di Studi Liguri, Monaco-Bordighera-Genova 1950, Bordighera 1952, pág. 29-40.

Pericot, L. y Maluquer, J., 1951: "La colección Bosoms. Materiales prehistóricos de Serinyà II». Monografías del Instituto de Estudios Pirenaicos, Zaragoza 1951, 73 páginas.

Peyrony, D., 1932: “Pièces pédonculées du Solutréen Supérieur français". AFAS Comptes rendus de la 56 session, Bruselas 1932, 3 páginas, 1 figura.

Peyrony, D. y Peyrony, E., 1938: “Laugerie-Haute prés des Eyzies (Dordogne)". Archives de l'Institut de Paléontologie Humaine, Mémoire núm. 19, 1938, 84 páginas.

RIPOLl LOPEZ, S., 1986: “El Solutrense de Cueva de Ambrosio (VélezBlanco, Almería) Campaña de 1963". EAE, núm. 148, 1986, 205 páginas, 109 figuras y 23 láminas.

- 1988: La Cueva de Ambrosio (Almería, España), y su posición cronoestratigráfica en el Mediterráneo Occidental. BAR, Serie Internacional, núm 462, (2 vols.), 596 páginas, 116 figuras y LV láminas.

SACCHI, D., 1976: "Les civilisations du Paléolithique Supérieur en Languedoc Occidental (Bassin de l'Aude) et en Roussillon". La Préhistoire Française, tomo 1, núm. 2, Paris 1976, pág. 1174-1189.

- 1986: “Le Paléolithique Supérieur du Languedoc Occidental et du Roussillon". XXI suplement de Gallia Préhistoire, París, CNRS, 1986, 284 páginas. 
SACCHI, D. y ABELANET, J., 1969: "Le Paléolithique Supérieur dans les Pyrennées Orientales". Cahiers Ligures de Préhistoire et d'Archéologie, vol. 18, 1969, pág. 9-12.

SMITH, Ph., 1966: Le Solutréen en France. Institut de Géologie du Quaternaire de Bordeaux, Impriméries Delmas, 1966, 450 páginas, 83 figuras.

Soler Masferrer, N., 1976a: El Paleolitic a les comarques Gironines. Servei d'Investigacions Arqueològiques de la Excma. Diputació de Girona; Centre d'Estudis Comarcals de Banyoles. Gerona, 1976, pág. 61-62.

- 1976b: Davant Pau. Servei d'Investigacions Arqueologiques de la Excma. Diputació de Girona; Centre d'Estudis Comarcals de Banyoles. Gerona 1976, páginas 147.

- 1976c: L'Arbreda. Servei d'Investigacions Arqueològiques de la Excma. Diputació de Girona; Centre d'Estudis Comarcals de Banyoles. Gerona 1976, pág. 148-152.

- 1986: Les industries del Paleolitic Superior en el Nord de Catalunya. Tésis Doctoral leida en la Universidad Central de Barcelona. 1986, inédita.

SONNEVILLE BORDES, D. de, 1973: "Sur le Paléolithique Supérieur de la Catalogne». Estudios dedicados al Prof. Dr. Luis Pericot (Trabajos eventuales, núm. 23), Barcelona 1970, pág. 61-66, 4 figuras. 